\title{
Epoxysilane Rearrangement: Mechanistic Studies and Synthetic Applications
}

\author{
Michiko Sasaki and Kei Takeda* \\ Department of Synthetic Organic Chemistry, Graduate School of Medical Sciences, Hiroshima \\ University,
}

Received June 28, 2006

\begin{abstract}
Mechanistic studies on and synthetic application of epoxysilane rearrangement, a novel synthetic use of $\alpha, \beta$-epoxysilanes, in which an anion-induced ring-opening of epoxide and Brook rearrangement in the resulting $\alpha$-silyl alkoxide occur in a tandem fashion to provide a $\beta$-siloxy allyl anion, are described.
\end{abstract}

\section{Introduction:}

Since the first synthesis of $\alpha, \beta$-epoxysilanes reported by Eisch $^{1}$ more than forty years ago, many kinds of $\alpha$, $\beta$-epoxysilanes have been synthesized and synthetic methodology based on their use has been developed. ${ }^{2}$ The seminal work of Stork and co-workers, ${ }^{3}$ who showed that $\alpha$, $\beta$-epoxysilanes can be converted to aldehydes and ketones via a ring-opening followed by desilylation, has stimulated considerable interest in their chemistry.

In this review we report a mechanistic aspect and synthetic applications of epoxysilane rearrangement, which is a novel synthetic use of $\alpha, \beta$-epoxysilanes and features transformation of $\beta$-silyl- $\alpha, \beta$-epoxy carbanion to $\beta$-siloxy allyl anion.

Thirteen years ago, we reported a new approach to the synthesis of highly functionalized cyclopentenol $\mathbf{5}$ using [3+ 2] annulation that involves a combination of $(\beta$-(trimethylsilyl)acryloyl)silane $\mathbf{1}$ as the three-carbon unit and lithium enolate $\mathbf{2}$ of alkyl methyl ketone as the two-carbon unit, which relies on the 1,3-sigmatropic shift in vinylcyclopropanolate 4 formed via a 1,2-anionic rearrangement of the silyl group (Brook rearrangement) ${ }^{4}$ in the 1,2-adduct 3 followed by internal carbonyl attack by the anion (Scheme 1). ${ }^{5}$

Scheme 1. Brook-rearrangement mediated [3+2] annulation.

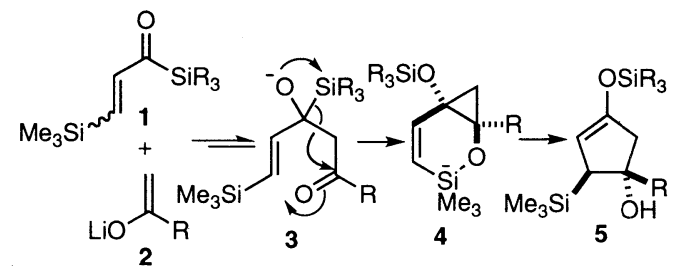

During the course of extension of this methodology to asymmetric versions, we had occasion to examine the reaction of $\beta$-silyl- $\alpha, \beta$-epoxyacylsilanes 6 with enolate of alkyl methyl ketone 7. Although we expected the formation of cyclopentenol derivatives 12 via a two-fold Brook rearrangement followed by an intramolecular aldol reaction, the major products were uncyclized enol silyl ether $\mathbf{1 0}$ and cyclopropanediol derivative 11, the latter being formed as a result of an intramolecular allylic attack on the carbonyl group by a siloxy carbanion generated by the second Brook rearrange-
Scheme 2. Attempted asymmetric Brook-rearrangement mediated $[3+2]$ annulation.

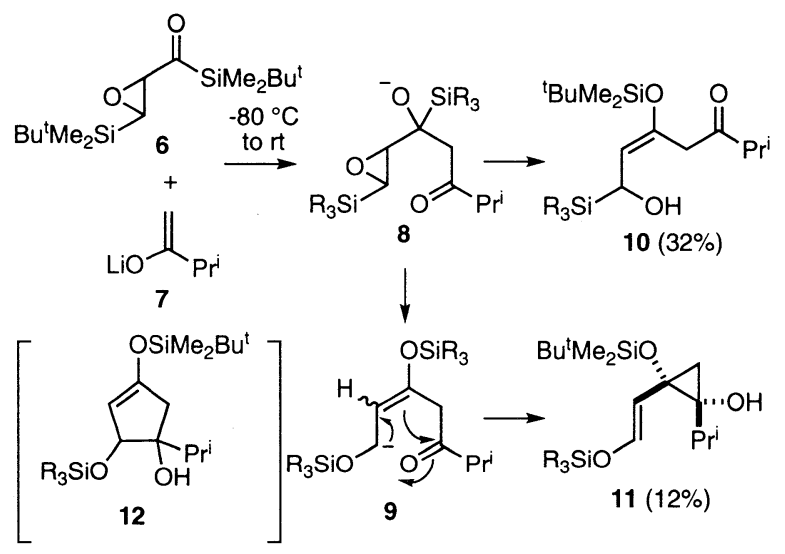

ment $(\mathbf{8} \rightarrow \mathbf{9})$ (Scheme 2).

This result indicated the possibility of the reaction of an epoxysilane 13 bearing an anion-stabilizing electron-withdrawing group at the $\alpha$-position with an amide base in the presence of an electrophile. If a tandem process that involves a base-promoted isomerization of the epoxide $(\mathbf{1 4} \rightarrow \mathbf{1 5})$, Brook rearrangement $(\mathbf{1 5} \rightarrow \mathbf{1 6})$, and a reaction of the resulting allylic anion with an electrophile $(\mathbf{1 6} \rightarrow \mathbf{1 7} \rightarrow \mathbf{1 8})$ proceeds well, the epoxysilane $\mathbf{1 3}$ would function as a homoenolate equivalent ${ }^{6}$ with synthetically useful functionality (Scheme 3).

Scheme 3. Tandem base-promoted ring-opening/Brook rearrangement/allylic alkylation of $\alpha, \beta$-epoxysilanes bearing an electron-withdrawing group at the $\gamma$-position.
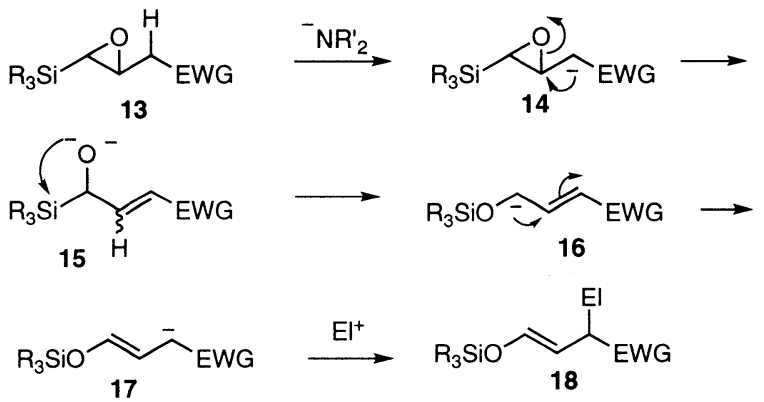
2. Tandem Base-promoted Ring-opening/Brook Rearrangement/Allylic Alkylation of $O$-Silyl Cyanohydrins of $\beta$-Silyl- $\alpha, \beta$-Epoxyaldehyde ${ }^{7}$

First, we chose $O$-silyl cyanohydrins of $\alpha, \beta$-epoxyaldehydes 19 bearing a nitrile group as the electron-withdrawing group as a substrate and investigated its reaction with a base in the presence of alkylating agents. When 19a and 19b were treated with LDA ( 1.1 equiv) in THF at $-80{ }^{\circ} \mathrm{C}$ in the presence of MeI (1.2 equiv) for $5 \mathrm{~min}, \alpha$-methylated cyanohydrins 20, products formed via a tandem sequence $(\mathbf{1 4} \rightarrow \mathbf{1 8})$, were obtained in $82 \%$ and $84 \%$ yields, respectively (Table 1).

Table 1. Tandem base-promoted ring-opening/Brook rearrangement/allylic alkylation of $O$-silyl cyanohydrins of $\beta$-silyl- $\alpha, \beta$-epoxyaldehyde.
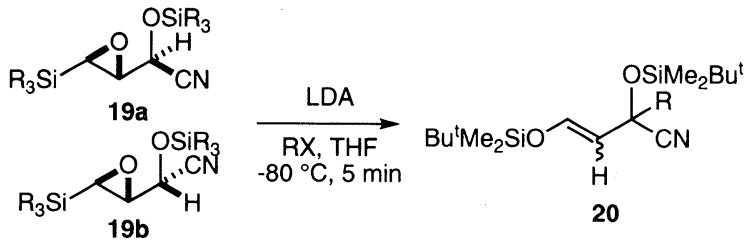

\begin{tabular}{lcc}
\hline & \multicolumn{2}{c}{20 , yield (\%) $(E / Z)$} \\
\cline { 2 - 3 } $\mathrm{RX}$ & from 19a & from 19b \\
\hline $\mathrm{Mel}$ & $82(2.5)$ & $84(22.0)$ \\
$\mathrm{Etl}$ & $76(2.9)$ & $74(28.0)$ \\
$i-\mathrm{Prl}$ & $58(2.8)^{a}$ & $74(31.0)$ \\
$\mathrm{PhCH}_{2} \mathrm{Br}$ & $86(2.7)$ & $98(47.0)$ \\
$\mathrm{CH}_{2}=\mathrm{CHCH}_{2} \mathrm{Br}$ & $83(3.4)$ & $87(40.0)$ \\
\hline \multicolumn{2}{l}{$a 12 \%$ yield of $20(\mathrm{R}=\mathrm{H})$} & was obtained.
\end{tabular}

It is particularly noteworthy that (1) the reactions were completed within $5 \mathrm{~min}$ at $-80{ }^{\circ} \mathrm{C}$ and alkylation products of possible intermediates other than $\mathbf{2 0}$ were not detected and (2) $E / Z$ ratios of $\mathbf{2 0}$ obtained from the two diastereomers were markedly different.

To obtain a better understanding of the reaction pathway, we first examined the effects of a cation and a base on the $E / Z$ selectivity of the reaction using lithium hexamethyldisilazide (LHMDS), sodium hexamethyldisilazide (NaHMDS), and potassium hexamethyldisilazide (KHMDS) (Table 2). While the use of lithium hexamethyldisilazide (LHMDS, 1.0 $\mathrm{M}$ in THF) resulted in lower yields but improvement in $E / Z$ ratios with 19a, comparable yields of 20 were obtained with potassium hexamethyldisilazide (KHMDS, $0.5 \mathrm{M}$ in toluene). It is notable that the increased formation of the $Z$-derivative with 19a was observed in the case of the latter base. The best results, in terms of yield and $E / Z$-selectivity, were obtained with sodium hexamethyldisilazide (NaHMDS, 1.0 M in $\mathrm{THF}$ ), allowing the formation of $(E)-\mathbf{2 0}$ in excellent yields.

Table 2. Effects of a cation and base on the $E / Z$ selectivity.

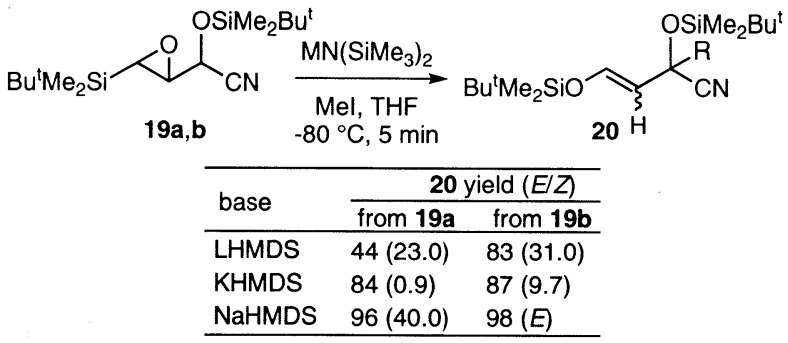

Since increased formation of the the $(Z)$-isomer was observed in the case of LDA and KHMDS, which contain hexane and toluene, respectively, we examined the effect of the counter cation ${ }^{8}$ using the same solvent system. However, the $E / Z$ selectivity in the reaction does not seem to strongly depend on the counter cation. The relationship between polarity of the solvent ${ }^{9}$ and $E / Z$ geometry of $\mathbf{2 0}$ was then investigated. The results are summarized in Table 3 . The use of less-polar solvents resulted in a substantial enhancement of $Z$-selectivity, suggesting that the nature of the solvent plays an important role in determination of $E / Z$ selectivity in the reaction.

Table 3. Effects of a solvent on the $E / Z$ selectivity.

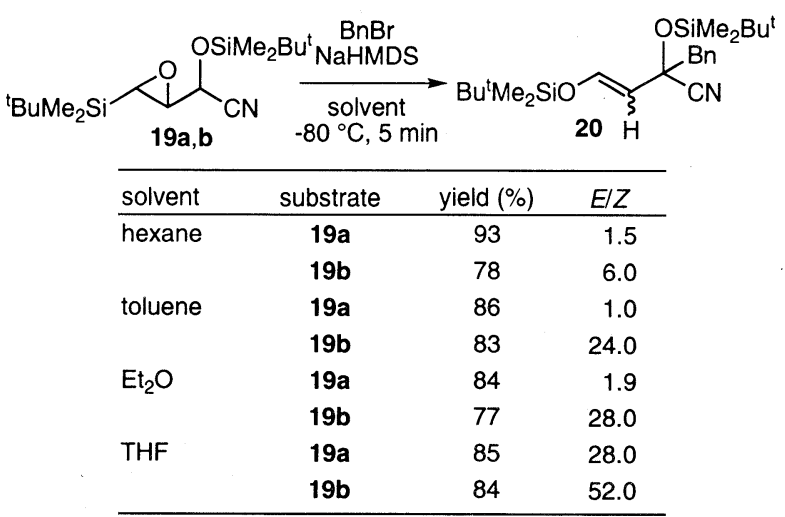

One possible explanation of these results is that the internal chelated structure $(Z)-\mathbf{2 1}$, which involves $\mathrm{M}-\mathrm{O},{ }^{10}$ is an immediate precursor to $(Z)-\mathbf{2 0}$ by alkylation. Thus, the poorer donor solvents help the intramolecular coordination of the siloxy group, therefore giving rise to the formation of $(Z)-\mathbf{2 0}$. This is supported by the results showing that $(Z)$-selectivity in the methylation of 19a,b with the bases was significantly lowered upon addition of HMPA, which can disrupt the chelated structure by solvating the cations (Table 4 ).

Table 4. Effects of addition of HMPA on the $E / Z$ selectivity.

\begin{tabular}{|c|c|c|c|c|c|}
\hline $\mathrm{E}_{2} \mathrm{OI}$ & $\int_{\mathbf{a}, \mathbf{b}}^{\mathrm{OSiMe}_{2}}$ & ${ }_{{ }_{2} \mathrm{Bu}^{\mathrm{t}} \mathrm{b}}^{\mathrm{b}}$ & $\begin{array}{l}F \\
5 \text { min }\end{array}$ & & + \\
\hline \multirow[b]{2}{*}{ substrate } & \multicolumn{2}{|c|}{ conditions } & \multicolumn{2}{|c|}{20} & 19 \\
\hline & base & HMPA & yield $(\%)$ & $E / Z$ & yield (\%) \\
\hline $19 a$ & LDA & $(-)$ & 82 & 2.5 & - \\
\hline $19 a$ & & $(+)$ & 61 & 28.0 & 26 \\
\hline $19 a$ & KHMDS & $(-)$ & 84 & 0.9 & - \\
\hline $19 a$ & & $(+)$ & 92 & 15.0 & - \\
\hline $19 b$ & LDA & $(-)$ & 84 & 22.0 & - \\
\hline $19 b$ & & $(+)$ & 85 & $E$ & 8 \\
\hline $19 b$ & KHMDS & $(-)$ & 87 & 9.7 & - \\
\hline $19 b$ & & $(+)$ & 84 & $E$ & - \\
\hline
\end{tabular}

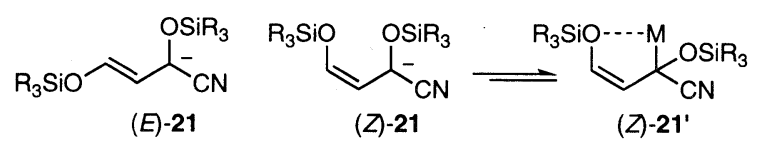

Although the intermediacy of a chelated species such as $(Z)-\mathbf{2 1}$ ' is consistent with the solvent effect on the $E / Z$ ratio of the product, it can not explain the fact that $\mathbf{2 0}$ was 
obtained from the two diastereomers $19 a, b$ in different $E / Z$ ratios in the cases of LDA and KHMDS, unless it is assumed that $(E)$ - and $(Z)-\mathbf{2 1}$ are formed from the starting cyanohydrins to a different extent depending on the stereochemistry of the starting cyanohydrins and on the solvent polarity and that they collapse to products before the establishment of an equilibrium. To determine whether alkylation occurs before equilibration, methyl iodide was added after addition of the base. The $E / Z$ ratios changed only slightly (Table 5), suggesting two possibilities.

Table 5. Alkylation of pregenerated $\beta$-siloxy allyl anions.

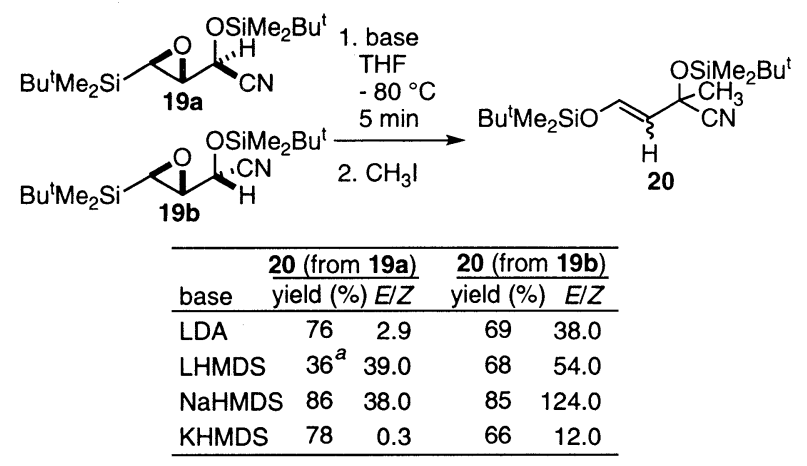

a $56 \%$ of 19 a was recovered.

One possibility is that $\mathbf{2 1}$ is an immediate precursor for the alkylation, isomerization between $(E)-$ and $(Z)-\mathbf{2 1}$ does not occur under the conditions, and the solvent effect for $E / Z$ selectivity operates in the earlier steps. The other possibility is that $\mathbf{2 1}$ is not an immediate precursor and the alkylation can occur in a concerted manner from intermediates that preserve stereochemical information originating from the starting materials and form in a ratio depending on the solvent polarity. The former possibility can be ruled out if the $E / Z$ isomerization between $(E)$ - and $(Z)-\mathbf{2 1}$ is proved to occur under the conditions.

To verify whether isomerization between $\left(E^{\prime}\right)$ - and $(\angle)-\mathbf{2 1}$ occurs, carbanions were generated by deprotonation of $(E)$ and $(Z)-\mathbf{2 2}$, which were prepared by quenching the reaction of 19b with NaHMDS in THF and 19a with KHMDS in $\mathrm{Et}_{2} \mathrm{O} /$ toluene, respectively, by acetic acid (Scheme 4 ). No or only slight $E / Z$-isomerization was observed regardless of the order of addition of the reagents when $(E)-\mathbf{2 2}$ and $(Z)-\mathbf{2 2}$ were treated with a base and methyl iodide under similar conditions to those for $\mathbf{1 9}$. These results cannot rule out the possibility of intermediacy of $\mathbf{2 1}$ in the reaction of $\mathbf{1 9}$.

Scheme 4. Base-induced alkylation of 22.

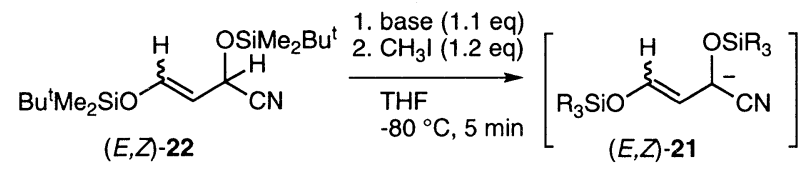

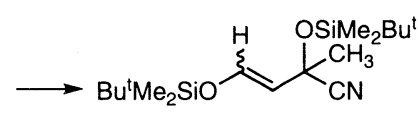

$(E, Z)-20$ base: LDA, LHMDS, NaHMDS, KHMDS

$(E)-22 \longrightarrow(E)-20$

$(Z)-22 \longrightarrow(Z)-20$

As a reaction pathway that can explain the above results, we propose a pathway in which a pentacoordinate silicate species, $(E)^{-}$and $(Z)-\mathbf{2 3}$, are formed first via addition of oxyanion, generated by ring-opening of the epoxide, to the silicon center, and then transformed into alkylation products $(E, Z) \mathbf{- 2 0}$ in a concerted manner or via allyl anion intermediates $\mathbf{2 1}$ (Scheme 5). Silicate $(E)-\mathbf{2 3}$ can be formed via $s y n$-elimination of 19a or anti-elimination of $\mathbf{1 9 b}$, and (Z) $-\mathbf{2 3}$ can be formed via anti-elimination of 19 a or syn-elimination of $\mathbf{1 9 b}$. After rotation around the $\mathrm{C} 3-\mathrm{C} 4$ bond in such a way that the $\mathrm{C} 4-\mathrm{Si}$ bond can adopt a parallel arrangement with the $\pi$ orbitals of the double bond, $(E)$ - and

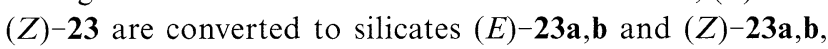
respectively, among which only $(Z)-\mathbf{2 3 a}$ can form an internally chelated structure with a metal cation. Consequently, if the chelated intermediate is responsible for the formation of $(Z)-\mathbf{2 3}$, the mode of ring-opening should be anti because $(Z)-\mathbf{2 0}$ is formed in a higher ratio from 19a than from $\mathbf{1 9 b}$ (see Table 1).

To determine the mode of ring-opening of the epoxide, we designed the following competitive experiment that relies on the fact that the conformational preference in $s y n^{-}$and anti-elimination acts in an opposite sense in the reaction of 19a and 19b. Thus, while the transition state from 19a is more favorable than that from $\mathbf{1 9 b}$ in the $s y n$-elimination in terms of less repulsive interactions between $\mathrm{H}-4$ and the $O$-silyl cyanohydrin moiety (A-value ${ }^{11}$ for $\mathrm{OSiMe}_{3}$ : 0.74 ; for $\mathrm{CN}: 0.2$ ), in the case of anti-elimination, the transition state from $19 b$ is more favorable. When a mixture of $19 \mathbf{a}$ (1 equiv) and 19b (1 equiv) in THF was treated with LDA (1 equiv) in the presence of MeI ( 1 equiv) at $-80{ }^{\circ} \mathrm{C}$ for $5 \mathrm{~min}$, a 1.0:0.7 mixture of 19a and 19b was obtained in $40 \%$ yield together with $35 \%$ of $20(E / Z=6.6)$, indicating that $19 \mathbf{b}$ is more reactive than is 19a (Table 6). These results are consistent with ant $i$-elimination, thus supporting the pathway described above. Furthermore, the concerted anti-deprotonation and ring- opening process was supported by the fact that the reactivities of $19 \mathrm{a}$ and $19 \mathrm{~b}$ were not affected by the addition of HMPA.

Further support for the proposed anti-elimination was also provided by reactions using cis-epoxysilanes, in which the difference between reactivities of the two diastereomers was expected to increase because of more severe steric repulsion between the siloxy and silyl groups in a transition state for anti-elimination.

The key question that needed to be addressed is why the mode of elimination in the case of $\mathbf{1 9}$ is anti, which is in sharp contrast to the widely accepted chelation-assisted syn-elimination mechanism for a base-promoted ring-opening. ${ }^{12,13}$ We speculated that the intramolecular chelated structure for the $s y n$-elimination is less favorable because partial formation of an oxygen-silicon bond occurs in the transition state leading to $\mathbf{2 3}$ from $\mathbf{1 9}$. To test this, we carried out a competitive experiment using $\mathbf{1 9 b}$ and $\mathbf{2 4 b}$, which bear electronically and sterically different silyl groups, anticipating that if the formation of the oxygen-silicon bond occurs after complete formation of the double bond, a difference between reactivities of $\mathbf{1 9 b}$ and $\mathbf{2 4 b}$ would not be observed (Table 7). When 19b (1 equiv) and $\mathbf{2 4 b}$ (1 equiv) were treated with LDA (1.4 equiv) in the presence of $\mathrm{CH}_{3} \mathrm{I}$ (1.4 equiv) in THF for 5 min, methylated derivatives $(E)-\mathbf{2 0}$ and $(E)-\mathbf{2 5}$ were obtained in a ratio of $3.1: 1$ together with recovery of the starting materials, $\mathbf{1 9 b}(18 \%)$ and $\mathbf{2 4 b}(40 \%)$, indicating that $\mathbf{1 9 b}$ is more reactive than $\mathbf{2 4 b}$. This result can be understood by assuming that $\mathrm{O}-\mathrm{Si}$ bond formation is involved in the rate-determining 
Scheme 5. A plausible reaction pathway.

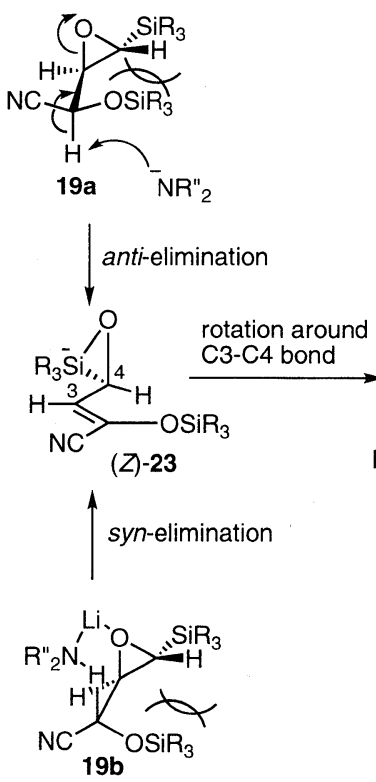

Table 6. Competition reaction between 19a and 19b.

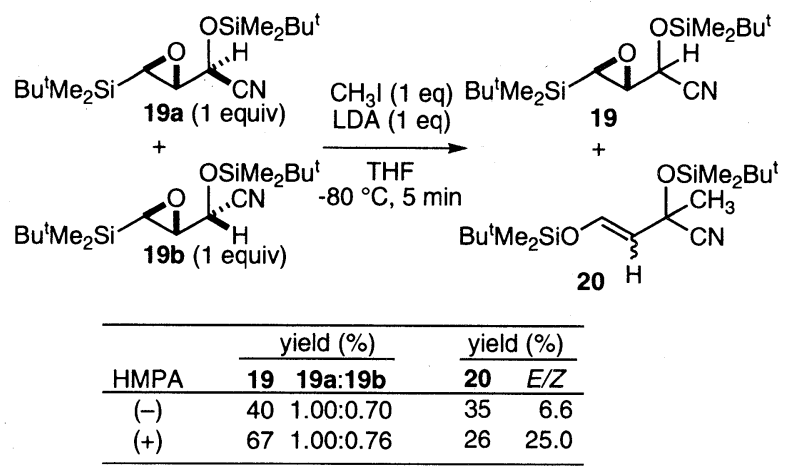

anti-elimination
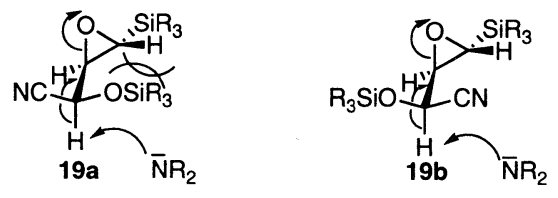

syn-elimination

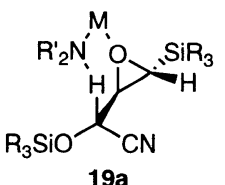

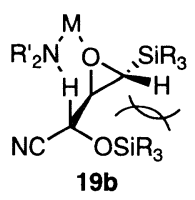

transition state and is more favorable in the $t$-butyldimethylsilyl group than in the $t$-butyldiphenylsilyl counter part, due to a steric factor rather than an electronical one, which would reflect the stabilization of the silicate ion by the phenyl group on the silyl group. Increased steric repulsion between a base and the silyl group in the proton abstraction, which is another possible factor explaining the result, proved to be less important on the basis of results of competitive experiments using less and more hindered bases, LiNEt $_{2}$ and lithium 2,2,6,6-tetramethylpiperidide (LTMP). Thus, reaction with $\mathrm{LiNEt}_{2}$ resulted in almost the same ratio of $(E)-\mathbf{2 0} /(E)-\mathbf{2 5}$, while the ratio was decreased in the reaction
Table 7. Competitive reaction between $19 \mathrm{~b}$ and $24 \mathrm{~b}$.

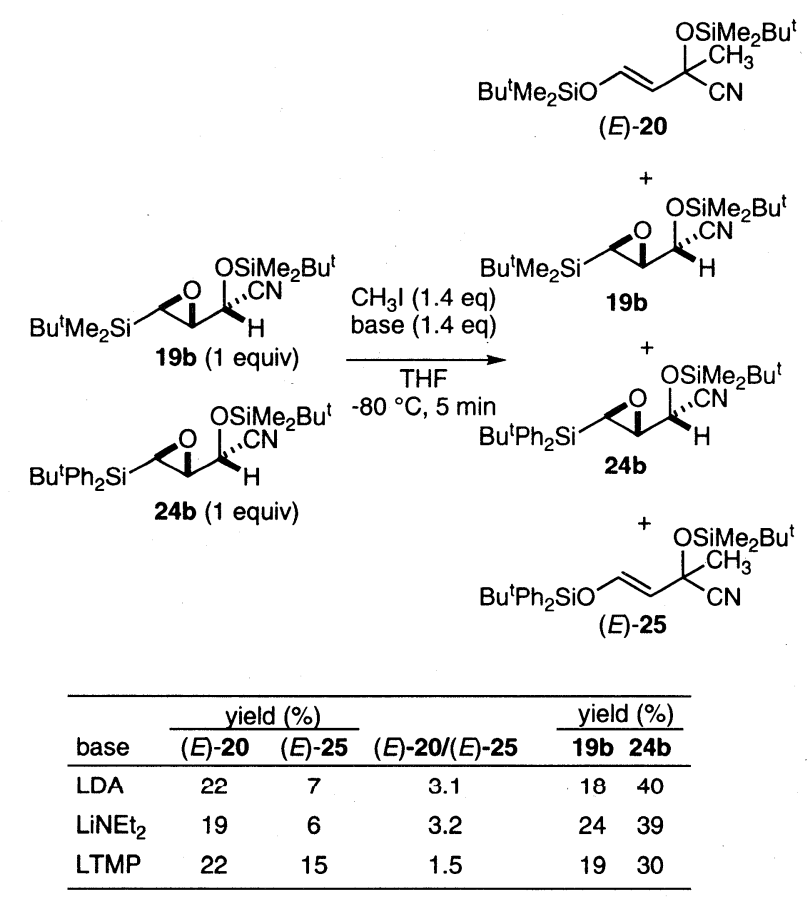

with LTMP. Therefore, the partial formation of an O-Si bond in the transition state can make the syn-elimination less favorable in the case of $\alpha$-silyl epoxide relative to substrates lacking an $\alpha$ silyl group.

\section{Synthetic Application of the Epoxysilane Rearrange- ment}

Based on the above described results showing that an $\alpha$, $\beta$-epoxysilane with an anion at the $\gamma$-position can function as an efficient trigger in cascade reactions, we decided to extend this tandem sequence to several synthetically useful reactions. We devised three different methods for the generation of a carbanion at the $\gamma$-position of the epoxysilanes, (1) deprotonation, (2) reaction of acylsilanes with a nucleophile 
Scheme 6. Methods for the generation of a carbanion at the $\gamma$-position of the epoxysilanes.

(1) deprotonation

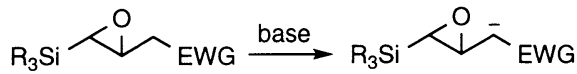

(2) reaction of acylsilanes with a nucleophile followed by Brook rearrangement
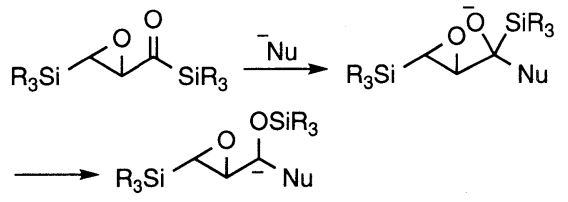

(3) a conjugate addition of a nucleophile to an enoate system bearing an epoxysilane moiety. at the $\alpha$-position

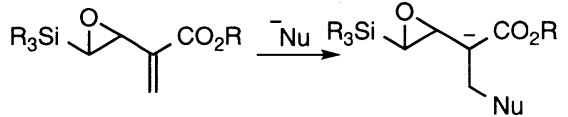

followed by Brook rearrangement, and (3) a conjugate addition of a nucleophile to an enoate system bearing an epoxysilane moiety at the $\alpha$-position (Scheme 6).

\subsection{Reaction of 26 with Bis-electrophile ${ }^{14}$}

During the investigation of the mechanism of the epoxysilane rearrangement using $\mathbf{2 6}$, an epoxysilane derivative bearing a nitrile group as an electron-withdrawing group and lacking a siloxy group, we observed that the reactions of 26 with MeI (1 equiv) in the presence of a base (1 equiv) afforded dimethylated enol silyl ethers as a major product, suggesting that the second deprotonation and methylation are very fast processes probably because of the small steric demand of the nitrile group. These results prompted us to examine the reaction with bis-electrophiles. ${ }^{15}$ When 26 was treated with NaHMDS in the presence of 1,4-dibromobutane at $-80{ }^{\circ} \mathrm{C}$, five-membered annulation product 27 was obtained in excellent yield. A similar result was obtained for the six-membered ring. Since the intramolecular alkylation proceeded well, we next examined the possibility of an annulation reaction using $\omega^{\text {-bromo- }}-\alpha, \beta$-unsaturatcd cstcrs. In the reaction leading to six- and seven-membered rings, the expected reaction, which involves a proton transfer in the Michael adducts followed by an intramolecular alkylation, ${ }^{16}$ occurred to give 28 . In contrast, in the reaction leading to a five-membered ring, instead, a Michael-Initiated-Ring-Closure, so-called MIRC reaction, ${ }^{17,18}$ involving conjugate addition to the enolate followed by an intramolecular alkylation before proton transfer, occurred to give 29 in $66 \%$ yield as a single diastereomer. The above results led us to examine the MIRC reaction of $\mathbf{2 6}$ with $\alpha, \omega$-bisenoates. ${ }^{19}$ When a mixture of 26 and 30 in THF-HMPA was treated with NaHMDS at $-98{ }^{\circ} \mathrm{C}$ for $15 \mathrm{~min}$, MIRC products 31a,b were obtained as a diastereomeric mixture (8:3) in $64 \%$ yield. This MIRC reaction seems to be affected by a subtle conformational difference; in fact, reaction of $\mathbf{2 6}$ with $\alpha, \omega$-bisenoates that would lead to a six-membered ring afforded only Michael addition products (Scheme 7).

\subsection{Nitrile Anion Cyclization with Epoxysilanes ${ }^{20}$}

We became interested in determining whether epoxysilane 32, a substrate in which one more carbon atom is introduced between the epoxide and the nitrile group in $\mathbf{2 6}$, could undergo the same type of reaction as that of $\mathbf{2 6}$. If so, epoxy nitrile
Scheme 7. Reaction of $\mathbf{2 6}$ with bis-electrophiles.

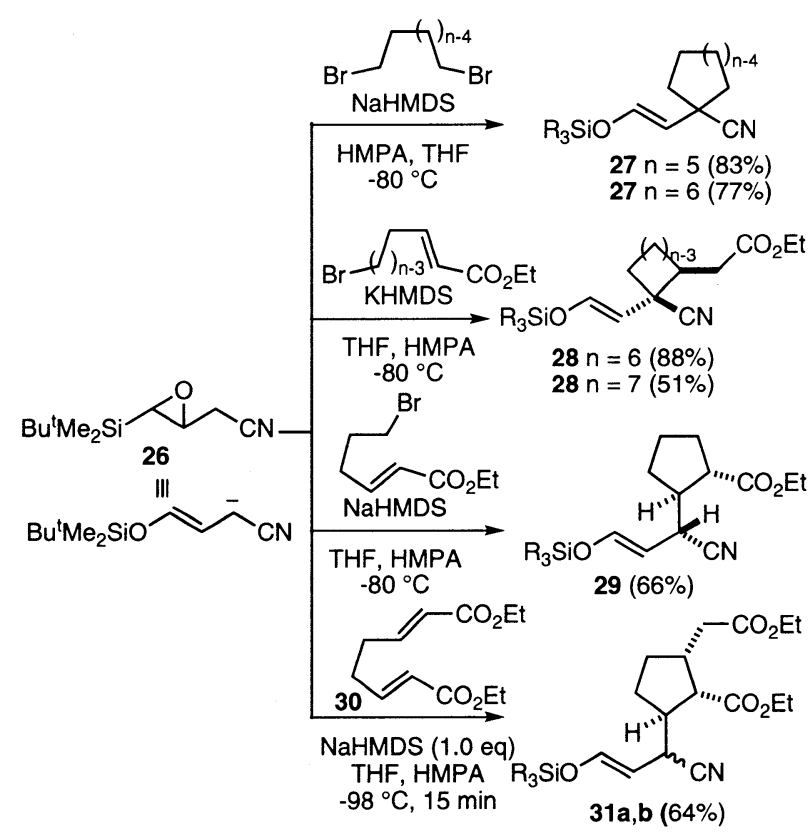

derivative 32 by reaction with a base would afford 36 via a tandem process that involves the formation of cyclopropane derivative $\mathbf{3 4}$ by epoxy nitrile cyclization followed by Brook rearrangement and an anion-induced cleavage of the cyclopropane ring. In this case, the nucleophilic characters of the $\alpha$-nitrile carbanions $\mathbf{3 3}$ and $\mathbf{3 5}$ might be critical factors in controlling the reaction. In contrast to the case of 19 , in which a base-promoted ring-opening proceeds in a concerted process via an anti-opening of the epoxide followed by the formation of an $\mathrm{O}-\mathrm{Si}$ bond, the three processes, cyclopropane formation from $33(33 \rightarrow 34)$, carbanion-mediated ring-opening of the cyclopropane $(\mathbf{3 4} \rightarrow \mathbf{3 5})$, and alkylation $(35 \rightarrow 36$ ), should be affected more by the nature of the carbanions. Thus, the ring-opening of the epoxide and the alkylation can be facilitated by increasing the nucleophilicity of the carbanions, whercas the cyclopropane ring cleavage can be enhanced by increasing the stability of the anion in $\mathbf{3 5}$.

Scheme 8. Nitrile anion cyclization with epoxysilanes followed by Brook rearrangement/ring-opening of cyclopropane nitriles/alkylation.
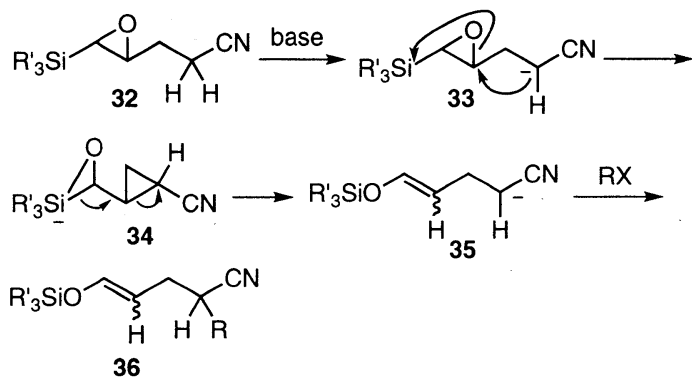

When trans $-\mathbf{3 7}(\mathrm{X}=\mathrm{H}, \mathrm{Ph}$ (diastereomeric mixture)) was treated with NaHMDS followed by the addition of MeI at $-15{ }^{\circ} \mathrm{C}$, methylated enol silyl ether $(Z)-\mathbf{3 8}$ was exclusively obtained (Scheme 9). The fact that the reaction of an $\alpha$-phenyl derivative required more forcing conditions suggests that the ring-opening of the epoxide is the slowest step. This is supported by the finding that treatment of one 
Scheme 9. Methylation of trans $-\mathbf{3 7}$

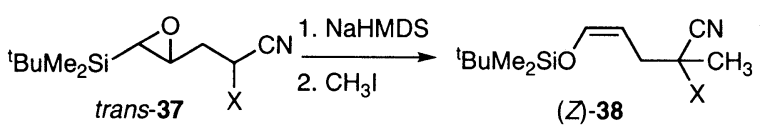

\begin{tabular}{cccc}
\hline $\mathrm{X}$ & NaHMDS & temperature & yield $(\%)$ \\
\hline $\mathrm{H}$ & 2 equiv & $-30^{\circ}$ to $5^{\circ} \mathrm{C}$ & 63 \\
$\mathrm{Ph}$ & 4 equiv & $-30^{\circ}$ to $15^{\circ} \mathrm{C}$ & 84 \\
\hline
\end{tabular}

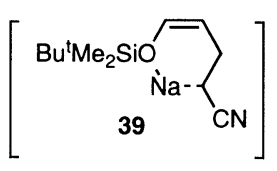

diastereomer of trans $-\mathbf{3 7}(\mathrm{X}=\mathrm{Ph})$ with $n-\mathrm{BuLi}$ at $-80{ }^{\circ} \mathrm{C}$ afforded a 1:1 mixture of the diastereomers in $87 \%$ yield.

It should be noted that $(E)-\mathbf{3 8}$ could not be detected even with addition of HMPA, suggesting that an internal chelation structure 39 is not responsible for the formation of the $(Z)$-isomer. The observed $Z$-selectivity can be explained by assuming the formation of silicate intermediate $\mathbf{4 0}^{21,22}$ via backside displacement of the epoxide by the $\alpha$-nitrile carbanion and the $\mathrm{O}-\mathrm{Si}$ bond formation followed by concerted processes involving Brook rearrangement and the anti-mode of eliminative ring fission of the cyclopropane from the rotamer 40' (Scheme 10), ${ }^{23}$ in which the C4-Si bond can adopt a coplanar arrangement with the $\mathrm{C} 2-\mathrm{C} 3$ bond. In this case, Brook rearrangement should occur with retention of configuration at the silyl-bearing carbon atom, because the $(E)$-derivative should be obtained if the rearrangement proceeds with inversion of configuration. ${ }^{24,25}$ If our analysis for the stereoselectivity is correct, the use of $\mathrm{cis}^{-}$-epoxide $\mathrm{cis}^{-\mathbf{3}} \mathbf{3 7}$ should provide $(E)$-enol silyl ether via 41'. To confirm this, we decided to examine the reaction of $c i s-37$.

In fact, exposure of $\mathrm{cis}^{-\mathbf{3} 7}$ to NaHMDS followed by methylation gave $(E)-\mathbf{3 8}$ in $71 \%$ yield (Scheme 11 ). No

Scheme 10. Stereochemical processes of base-mediated isomerization of trans- and cis $^{-37}$.
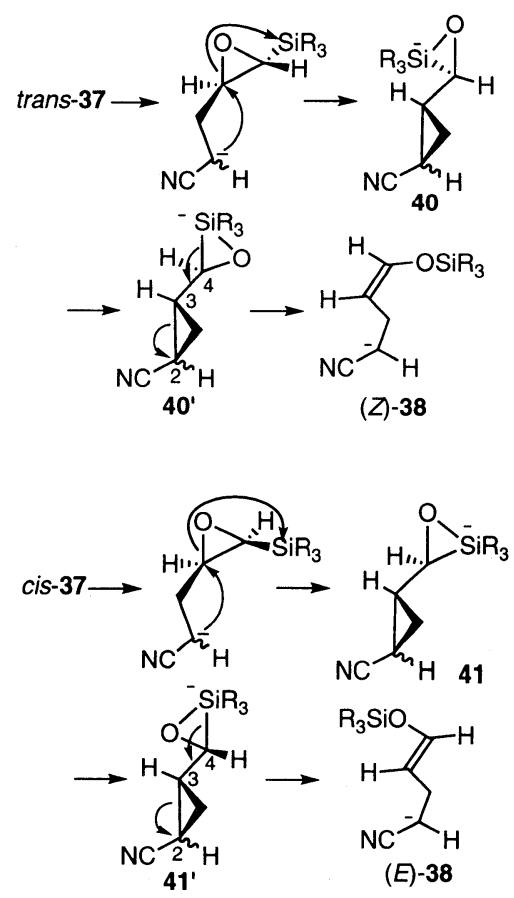

(Z)-enol silyl ether derivative was detected. The observed stereospecificity is compatible with the concerted pathway shown in Scheme 10.

Scheme 11. Methylation of $c i s-37$.

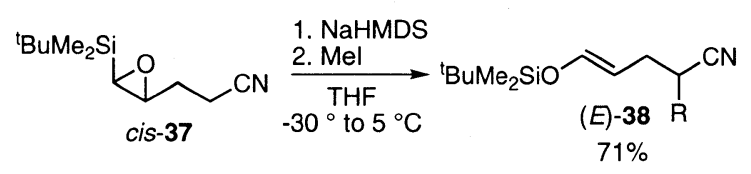

\section{3 $\gamma$-p-Toluenesulfonyl- $\alpha, \beta$-Epoxysilane as an Acrolein $\boldsymbol{\beta}$-Anion Equivalent ${ }^{26}$}

$\alpha, \beta$-Unsaturated aldehyde is an important structural moiety as a synthetic intermediate in a variety of chemical transformations as well as in diverse classes of bioactive organic molecules. Consequently, much effort has been devoted to the development of synthetic methods for the functionality. Among these, the most general and commonly used methods include Wittig-type homologation reaction ${ }^{27}$ and the use of $\beta$-acyl vinyl anion equivalents. ${ }^{28}$ Most of these methods, however, require relatively harsh reaction conditions to unmask the $\alpha, \beta$-unsaturated aldehyde. We envisioned that introduction of a leaving group that can stabilize a carbanion instead of the nitrile group would produce $\mathbf{4 2}$, which can be easily transformed into conjugate aldehyde $\mathbf{4 4}$ via desilylation with concomitant elimination of the leaving group in $\mathbf{4 3}$ (Scheme 12).

Scheme 12. Epoxysilanes 42 as an acrolein $\beta$-anion equivalent.

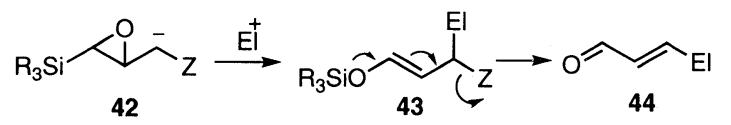

We examined a variety of leaving groups, including pyridin-2-sulfinyl, phenylsulfonyl and $p$-toluenesulfonyl. Among them, $p$-toluenesulfonyl derivative 46, which was prepared from the known epoxy silane $\mathbf{4 5}$ readily derived from propargyl alcohol, was found to provide the best result. ${ }^{29}$ When NaHMDS was added to a cooled $\left(-80{ }^{\circ} \mathrm{C}\right)$ solution of 46 and benzyl bromide and the reaction mixture was allowed to warm to $-60{ }^{\circ} \mathrm{C}$ over a period of $30 \mathrm{~min}$, enol silyl ether 47 was obtained in $93 \%$ yield. Conversion of $\mathbf{4 7}$ to conjugated aldehyde 48a was carried out by treatment with $n-\mathrm{Bu}_{4} \mathrm{NF}$ in $86 \%$ yield (Scheme 13). It should be noted that $\mathbf{4 6}$ does not need chromatographic purification and possesses excellent shelf stability at room temperature.

Scheme 13. Preparation of $\mathbf{4 6}$ and its reaction with $\mathrm{PhCH}_{2} \mathrm{Br}$ followed by demasking to $\mathbf{4 8}$.

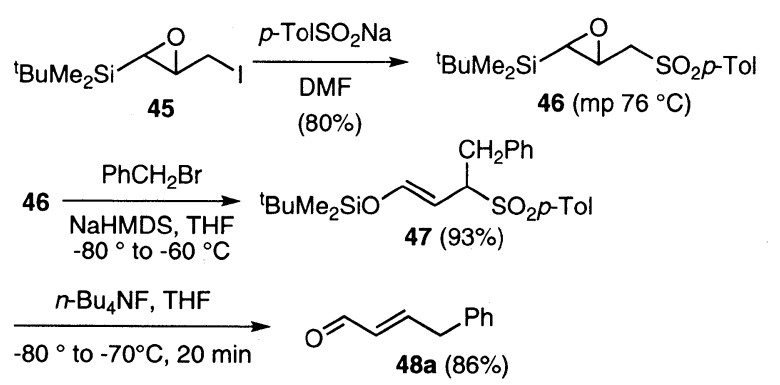

The entire reactions could be carried out in a one-pot process by the addition of ethanol, which can enhance the 
solubility of TBAF at a lower temperature and lower the nucleophilicity of the resulting sulfinate derivatives. The reaction was also successful with alkyl halides bearing functional groups such as siloxy and ester and with an aldehyde to give $\alpha, \beta$-unsaturated aldehydes 48 and 49 (Tables 8, 9).

Table 8. One-pot synthesis of $\mathbf{4 8}$.

\begin{tabular}{|c|c|c|}
\hline${ }^{\mathrm{t}} \mathrm{BuMe}_{2} \mathrm{Si} \overbrace{46}^{\mathrm{SO}_{2} \mathrm{Tol}}$ & $\begin{array}{l}\text { 1. } \mathrm{RX}(1.0 \mathrm{eq}) \\
\underset{\mathrm{NaHMDS}(1.0 \mathrm{eq})}{\mathrm{THF}} \\
\text { 2. } n-\mathrm{Bu}_{4} \mathrm{NF}(1.0 \mathrm{eq}) \\
\mathrm{EtOH}(3.0 \mathrm{eq})\end{array}$ & $48 a-e$ \\
\hline $\mathrm{RX}$ & conditions & yield $(\%)$ \\
\hline $\mathrm{BrCH}_{2} \mathrm{Ph}$ & $\begin{array}{l}\text { 1. }-80^{\circ} \text { to }-60^{\circ} \mathrm{C}, 30 \mathrm{~min} \\
\text { 2. }-80^{\circ} \text { to }-70^{\circ} \mathrm{C}, 15 \mathrm{~min}\end{array}$ & 85 \\
\hline $\mathrm{ICH}_{2}\left(\mathrm{CH}_{2}\right)_{6} \mathrm{CH}_{3}$ & $\begin{array}{l}\text { 1. }-80^{\circ} \text { to }-50^{\circ} \mathrm{C}, 40 \mathrm{~min} \\
\text { 2. }-80^{\circ} \text { to }-70^{\circ} \mathrm{C}, 20 \mathrm{~min}\end{array}$ & 84 \\
\hline $\mathrm{BrCH}_{2} \mathrm{CH}=\mathrm{CH}\left(\mathrm{CH}_{2}\right)_{4} \mathrm{CH}_{3}$ & $\begin{array}{l}\text { 1. }-80^{\circ} \text { to }-50^{\circ} \mathrm{C}, 30 \mathrm{~min} \\
\text { 2. }-80^{\circ} \text { to }-70^{\circ} \mathrm{C}, 15 \mathrm{~min}\end{array}$ & 82 \\
\hline $\mathrm{ICH}_{2} \mathrm{CH}_{2} \mathrm{CH}_{2} \mathrm{CH}_{2} \mathrm{OSiMe}_{2} \mathrm{Bu}^{\prime}$ & $\begin{array}{l}\text { t. }-80 \text { to }-40^{\circ} \mathrm{C}, 45 \mathrm{~min} \\
\text { 2. }-80^{\circ} \text { to }-70^{\circ} \mathrm{C}, 15 \mathrm{~min}\end{array}$ & 68 \\
\hline $\mathrm{ICH}_{2} \mathrm{CH}_{2} \mathrm{CH}_{2} \mathrm{CO}_{2} \mathrm{Et}$ & $\begin{array}{l}\text { 1. }-80^{\circ} \mathrm{C}, 5 \mathrm{~min} \text {; then } \mathrm{RX} \\
-80^{\circ} \text { to }-40^{\circ} \mathrm{C}, 45 \mathrm{~min} \\
\text { 2. }-80^{\circ} \text { to }-70^{\circ} \mathrm{C}, 20 \mathrm{~min}\end{array}$ & 74 \\
\hline
\end{tabular}

Table 9. One-pot synthesis of 49.

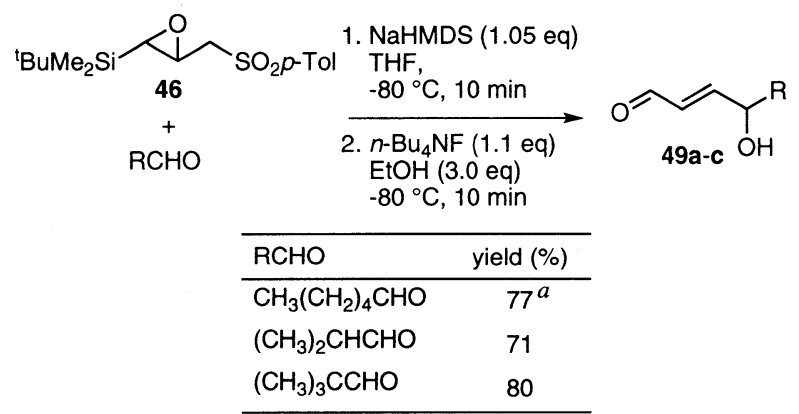

${ }^{a} \mathrm{CH}_{3} \mathrm{COOH}$ (1.0 eq) was added in the desilylation.

\subsection{Two-fold Brook Rearrangement-mediated Tandem Reactions of $\delta$-Silyl- $\gamma, \delta$-Epoxy- $\alpha, \beta$-Unsaturated Acylsilanes with a Cyanide Ion $^{30,21}$}

We previously reported that the reaction of acylsilanes with a cyanide ion produces an $\alpha$-siloxy nitrile carbanion via Brook rearrangement. ${ }^{31}$ The rearrangement is a very facile process because of the anion-stabilizing nature of a cyano group. We conceived the idea that the $\alpha$-cyano carbanion could induce epoxysilane rearrangement and focused on epoxysilane $\mathbf{5 0}$ because the parent compound, lacking the double bond between acylsilane and epoxysilane moieties, could not be prepared in reasonable yield.

First, to test the feasibility of this approach, we examined the reaction with $\mathrm{KCN}$ in $\mathrm{CH}_{2} \mathrm{Cl}_{2}-\mathrm{H}_{2} \mathrm{O}$ on the basis of the previous result. When acryloylsilane $\mathbf{5 0}$ was treated with $\mathrm{KCN}$ in the presence of $n-\mathrm{Bu}_{4} \mathrm{PBr}$ in $\mathrm{CH}_{2} \mathrm{Cl}_{2}-\mathrm{H}_{2} \mathrm{O}, O$-silyl cyanohydrin derivative $\mathbf{5 5}$ was obtained together with $\alpha$-silyl alcohol 54, a product that was protonated before the formation of the second silicate intermediate 53 (Table 10). ${ }^{32}$ The fact that $\mathbf{5 0}$ can undergo a two-fold Brook rearrangement in the presence of water to give $\mathbf{5 5}$ as a major product without interception of intermediates such as $\mathbf{5 1}$ by water prompted us to examine the reaction of $\mathbf{5 0}$ with electrophiles in non-hydroxylic solvents.
Table 10. Reaction of $\mathbf{5 0}$ with $\mathrm{KCN}$ under liquid-liquid phase-transfer catalytic conditions.

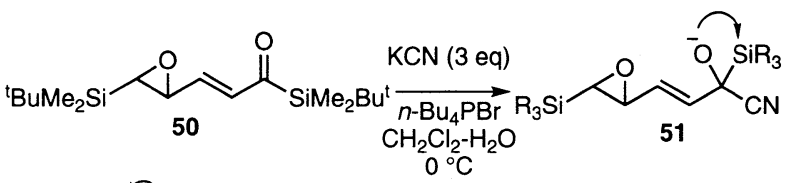

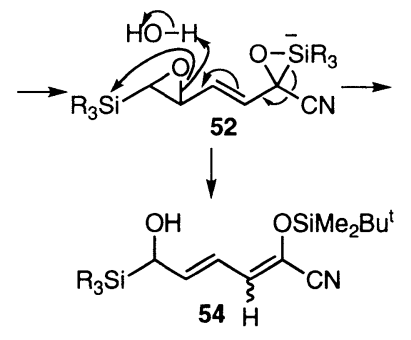

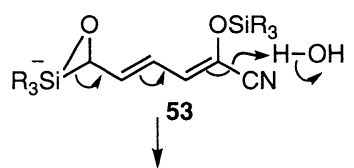<smiles>COC(C)(C)C=CC=COC(C)(C)C</smiles>

\begin{tabular}{ccccc}
\hline & & & \multicolumn{2}{c}{ products (\%) } \\
\cline { 3 - 5 } catalyst & mol\% & time (h) & $\mathbf{5 4}$ & $\mathbf{5 5}(E / Z)$ \\
\hline${ }^{n} \mathrm{Bu}_{4} \mathrm{PBr}$ & 0.5 & 7.5 & 42 & 34 (only E) \\
${ }^{n} \mathrm{Bu}_{4} \mathrm{PBr}$ & 5 & 1.5 & 32 & $31(6.75)$ \\
${ }^{n} \mathrm{~B} u_{4} \mathrm{PBr}$ & 50 & $5(\mathrm{~min})$ & 5 & $50(0.72)$ \\
\hline
\end{tabular}

Among the electrophiles in combination with $\mathrm{KCN}$ tested, cyanoformates ${ }^{33}$ provided the best results in terms of reaction rate and yield (Table 11). Thus, treatment of $\mathbf{5 0}$ with cyanforamate in the presence of catalytic amounts of $\mathrm{KCN}$ and $18-$ crown -6 afforded highly functionalized dienol silyl ether derivatives via a tandem sequence featuring a two-fold Brook rearrangement.

Table 11. Reaction of $\mathbf{5 0}$ with cyanoformates.

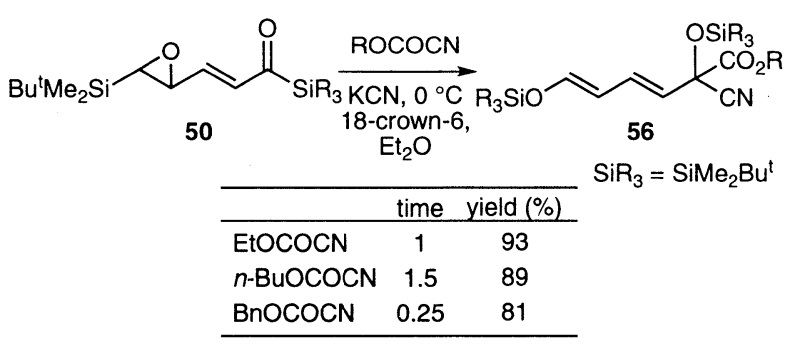

3.5 Formation of Functionalized Cyclopropane Derivatives via Epoxysilane Rearrangement Induced by a Carbanion Generated by Conjugate Addition of Enolates of Chloroacetate and $\boldsymbol{\alpha}$-Chloroacetamide ${ }^{34}$

The third method for generating a carbanion at the neighboring position of the epoxysilanes involves the Michael addition of nucleophile onto enoates bearing an epoxysilane moiety at the $\alpha$-position. After an extensive search for the combination of an enoate with a nucleophile, we found that an enoate 57, which has a double bond between an epoxysilane and an enoate moiety, is a suitable substrate in terms of the ease of preparation. Also, an internal nucleophile-electrophile such as an enolate of $\alpha$-haloester, which can trap the anion generated by the epoxysilane rearrangement before decomposition, was found to serve as an effective nucleophile. Treatment of 57 with the potassium enolate ${ }^{35}$ of ethyl chloroacetate in THF at $-80{ }^{\circ} \mathrm{C}$ to $-60{ }^{\circ} \mathrm{C}$ afforded cyclopropanediolate derivatives $\mathbf{5 8 a}$ and $\mathbf{5 8 b}$ with predominant formation of a cis-isomer (Table 12).

The more favorable formation of the cis-isomer can be explained as being a consequence of chelation in which the two ester groups are involved, since addition of HMPA 
Table 12. Reaction of $\mathbf{5 7}$ with the potassium enolate of ethyl chloroacetate.

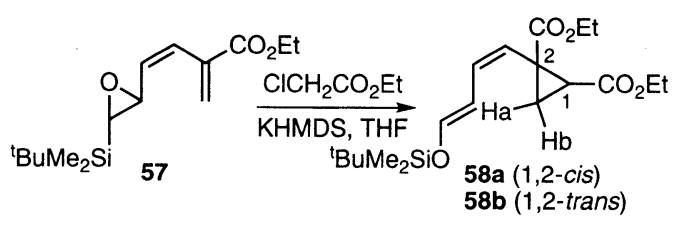

\begin{tabular}{cc}
\hline conditions & yield (\%) (58a/58b) \\
\hline$-80^{\circ} \mathrm{C}$ to $-60^{\circ} \mathrm{C}$ & $75(1.0: 0.5)$ \\
$-98{ }^{\circ} \mathrm{C}$ & $85(1.0: 0.2)$ \\
HMPA $(10 \%),-80^{\circ} \mathrm{C}$ to $-60^{\circ} \mathrm{C}$ & $76(0.7: 1.0)$
\end{tabular}

resulted in a reversal of selectivity. We speculated that stabilization of the chelation structure would enhance the selectivity, and we focused on the use of lithium enolate of chloroacetamides from the point of view that the higher reactivity of the enolates and the stronger chelating ability of the amide function and of the lithium cation are sufficient to compensate for the lower reactivity of lithium enolates relative to potassium enolates. When $\mathbf{5 7}$ was treated with the lithium enolate of $N, N$-diethylchloroacetamide, the corresponding cyclopropane derivative 59a was obtained as a single diastereomer in an excellent yield (Table 13).

Table 13. Reaction of $\mathbf{5 7}$ with the lithium enolate of $N, N$-diethylchloroacetamide.

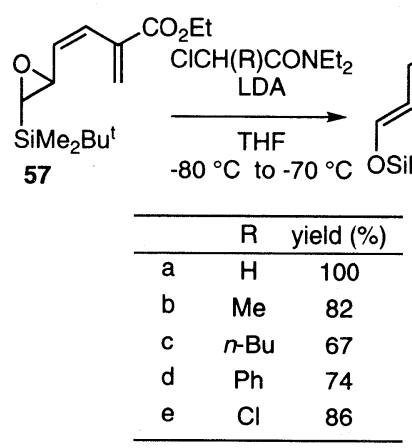

A plausible reaction pathway that accounts for the stereochemical outcome of the reaction of $\mathbf{5 7}$ is outlined in Scheme 14. The exclusive formation of the internal $(Z)$-olefin in the reactions of both ester and amide enolates can be understood by assuming that silicate intermediate $\mathbf{6 1}$ reacts in a $s^{-}$-cis diene conformation and faster than the change in the conformation of the diene moiety in $\mathbf{6 1}$ to give $\mathbf{6 2}$. The enolate $\mathbf{6 2}$ can undergo either or both of two reaction pathways, intramolecular alkylation to give 58a and $\mathbf{5 8 b}$ and formation of the chelation structures 63 and 64 , depending on the stability of the chelation structures. The fact that reactions with lithium enolate of $\alpha$-chloroacetamide give the cis-derivative exclusively can be understood in terms of the stronger chelating ability of the lithium cation and of the amide function.

\section{Chirality Transfer from Epoxide to Carbanion ${ }^{36}$}

Enantiomerically pure chiral epoxides are now among the most important intermediates for organic synthesis because of their ready availability and high versatility. ${ }^{37}$ Their chiralities have been extensively utilized for the establishment of one or more than two chiral centers via ring-opening reactions. During the mechanistic studies on epoxysilane rear-
Scheme 14. Plausible reaction pathway.

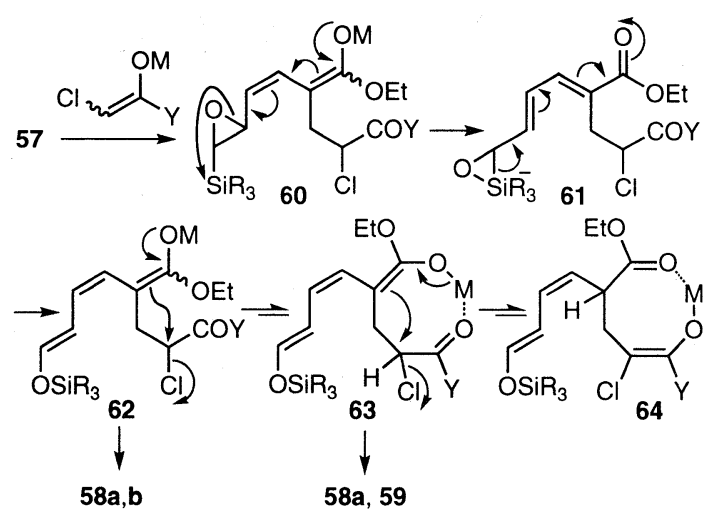

rangement, ${ }^{7 \mathrm{~b}}$ we became interested in the novel use of epoxide as a chiral source, in which the chirality can be transferred to remote positions via a cascade sequence triggered by chirality transfer of epoxide into a formal carbanion.

First, we examined the reaction of enantiomerically enriched epoxysilane 19a with a base in the presence of benzyl bromide, anticipating direct alkylation from an allylsilicate derivative $\mathbf{2 3}$ (Scheme 5), a possible intermediate in the epoxysilane rearrangement, without involvement of a carbanion intermediate 21. Unfortunately, benzylated rearrangement products $(E)$ - and $(Z)-\mathbf{2 0}$ obtained under a variety of conditions were completely racemic (Scheme 15).

Scheme 15. Epoxysilane rearrangement using optically enriched 19a.

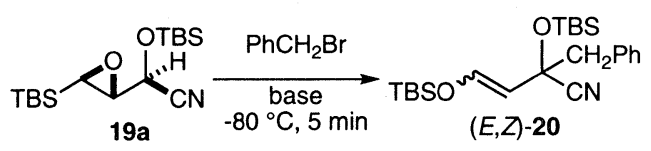

We attributed the racemization to the slower reaction with an electrophile because of the intermolecular process. We therefore decided to change the reaction with an electrophile from an intermolecular to intramolecular process and focused on trapping of the generated carbanion by $[2,3]-$ Wittig rearrangement ${ }^{38}$ as shown in Scheme 16.

Scheme 16. Tandem epoxysilane rearrangement/[2,3]-Wittig rearrangement.

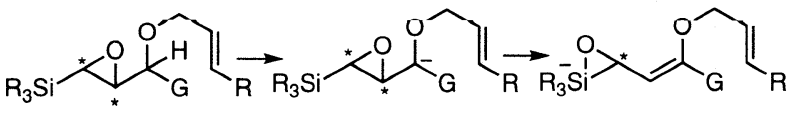

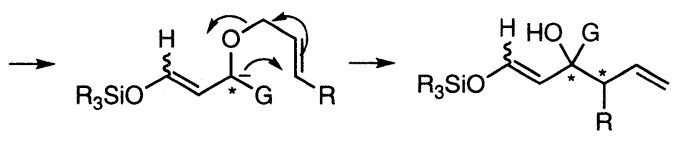

First, we examined the reaction under a variety of conditions using a model compound $\mathbf{6 5}$, but the starting material was recovered. Since the failure of the reaction was attributed to insufficient acidity of the proton at $\mathrm{C}-1$ and a sterically congested environment around the proton, we attempted to introduce a double bond between the epoxysilane moiety and the aryl substituent. Among the substrates examined, the 2-naphthyl derivatives 66a and $\mathbf{6 6} \mathbf{b}$ provided the best results in terms of separability of diastereomers (Figure 1).

When optically enriched 66a was treated with $n$-BuLi (2.0 
<smiles>CC(C)(C)[Si]C1OC2C1OC2([18OH])c1ccccc1</smiles>

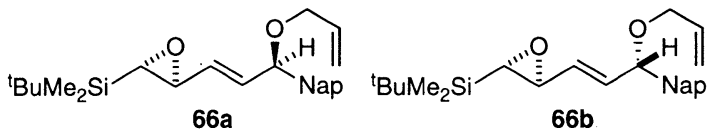

Figure 1

equiv) in THF, the most common solvent for [2,3]-Wittig rearrangement, for $5 \mathrm{~min}$ at $-80^{\circ}$ to $-75^{\circ} \mathrm{C}$, the tandem rearrangement products $(E)-$ and $(Z)-67$ were obtained in $46 \%$ yield and in racemic form (Table 14 , entry 1 ). The fact that the asymmetric induction was observed in the solvent at higher temperatures, albeit in poor yield, (entry 3) prompted us to change the solvent to other ethereal solvents, resulting in dramatic improvement in the asymmetric induction (entries 5-8). The use of 1,4-dioxane ${ }^{39}$ provided excellent enantiomeric purity (entries 7 and 8 ).

Table 14. Tandem epoxysilane rearrangement/[2,3]-Wittig rearrangement of $\mathbf{6 6 a}$.

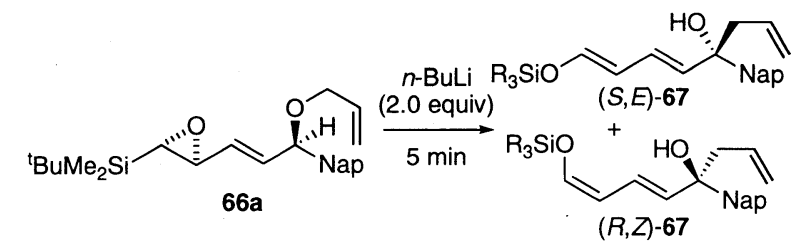

\begin{tabular}{|c|c|c|c|c|c|c|c|}
\hline entry & solvent & temperature & yield $(\%)$ & $\begin{array}{c}\text { recovered } \\
\mathrm{SM}^{2}(\%)\end{array}$ & $E: Z$ & & $\begin{array}{c}\%)^{b} \\
Z\end{array}$ \\
\hline 1 & THF & $-80^{\circ}$ to $-75^{\circ} \mathrm{C}$ & 46 & 45 & 5.3:1 & 0 & 0 \\
\hline 2 & THF & $-35^{\circ}$ to $-30^{\circ} \mathrm{C}$ & 88 & - & $2.4: 1$ & 0 & 0 \\
\hline 3 & THF & $25^{\circ}$ to $30^{\circ} \mathrm{C}$ & 80 & - & $1.2: 1$ & 7 & 0 \\
\hline 4 & $\mathrm{Et}_{2} \mathrm{O}$ & $-80^{\circ}$ to $-75^{\circ} \mathrm{C}$ & 0 & 94 & - & - & - \\
\hline 5 & $\mathrm{Et}_{2} \mathrm{O}$ & $-35^{\circ}$ to $-30^{\circ} \mathrm{C}$ & 45 & 35 & $1: 9.5$ & 81 & 74 \\
\hline 6 & $\mathrm{Et}_{2} \mathrm{O}$ & $25^{\circ}$ to $30^{\circ} \mathrm{C}$ & 72 & - & $1: 6.8$ & 84 & 80 \\
\hline 71 & ,4-dioxane & $25^{\circ}$ to $30^{\circ} \mathrm{C}$ & 85 & - & $1: 2.6$ & 96 & 74 \\
\hline 81 & 1,4-dioxane & $50^{\circ}$ to $60^{\circ} \mathrm{C}$ & 82 & - & $1: 2.6$ & 91 & 82 \\
\hline
\end{tabular}

${ }^{a} \mathrm{SM}=$ starting material.

${ }^{b}$ Corrected for ee of the starting material $(90 \%$ ee).

Reaction of diastereomer $\mathbf{6 6 \mathbf { b }}$ proceeded in a similar manner to give $(R, E)-$ and $(S, Z)-\mathbf{6 7}$, which are enantiomeric to those obtained from 66a, respectively (Table 15).

Table 15. Tandem epoxysilane rearrangement/[2,3]-Wittig rearrangement of $\mathbf{6 6 b}$

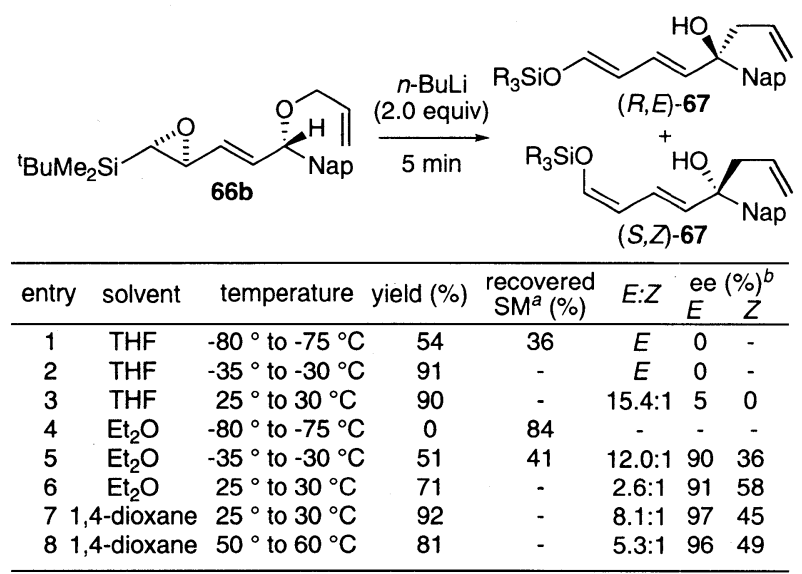

a $\mathrm{SM}=$ starting material.

${ }^{b}$ Corrected for ee of the starting material $(91 \%$ ee).
It should be noted that chirality of a carbanion derived from the epoxide, conjugated with both a naphthyl group and a double bond, can be retained even at above room temperature. The results are consistent with two reaction pathways, (1) the formation of a carbanion precursor in a concerted manner followed by $[2,3]$-Wittig rearrangement before racemization $(66 \rightarrow 68 \rightarrow 69 \rightarrow 67)$ and (2) the direct formation of $[2,3]$-Wittig rearrangement products from a silicate derivative, a possible intermediate in the Brook rearrangement, without involvement of a carbanion intermediate $(\mathbf{6 6} \rightarrow \mathbf{6 8}$ $\rightarrow$ 67)(Scheme 17).

Scheme 17. Possible reaction pathways for the tandem epoxysilane rearrangement/[2,3]-Wittig rearrangement.
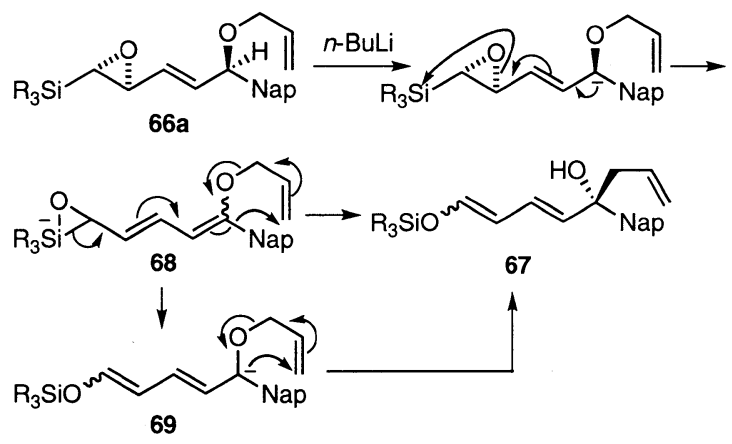

To obtain insight into the reaction pathway, we decided to examine [2,3]-Wittig rearrangement of optically enriched $(S)-70,{ }^{40}$ in which a carbanion is generated by direct protonation and racemization may be more facile. If the reaction of $\mathbf{7 0}$ results in complete racemization, the possibility of a pathway involving a carbanion intermediate would be ruled out. Although no asymmetric induction was observed in THF, reactions in 1,4-dioxane were found to show the best enantioselectivity again to give $(R)-\mathbf{7 1}$ (Table 16 , entries 1 and 4). It is notable that less enantioselectivity was observed at a lower temperature in $\mathrm{Et}_{2} \mathrm{O}$ (entries 2 and 3), suggesting that the loss of chirality is at least partly attributed to racemization duc to the dccrcascd ratc of the $[2,3]$ Wittig rcarrangcment at a lower temperature. These results are consistent with the intermediacy of a chiral carbanion, although the possibility of epoxysilane rearrangement/[2,3]-Wittig rearrangement in a concerted manner cannot be ruled out. The origin of the excellent enantioselectivity observed in 1,4-dioxane is unclear at present, but it might be due to the decreased rate of racemization by chelation of the lithium cation with the two oxygens. This is supported by the fact that the addition of HMPA in 1,4-dioxane (entry 5) and the use of 1,3-dioxane (entry 6 ) resulted in complete racemization.

\section{Conclusion}

In this account, we have demonstrated the development of epoxysilane rearrangement, results of its mechanistic studies and synthetic application. The rearrangement could trigger a reaction cascade that eventually can achieve a large increase in complexity in one operation and in a stereoselective manner. Moreover, results of mechanistic studies on the rearrangement led to a conceptually novel approach to the chirality transfer in which epoxide chirality can be transferred into carbanion. 
Table 16. [2,3]-Wittig rearrangement of $(S)-\mathbf{7 0}$.

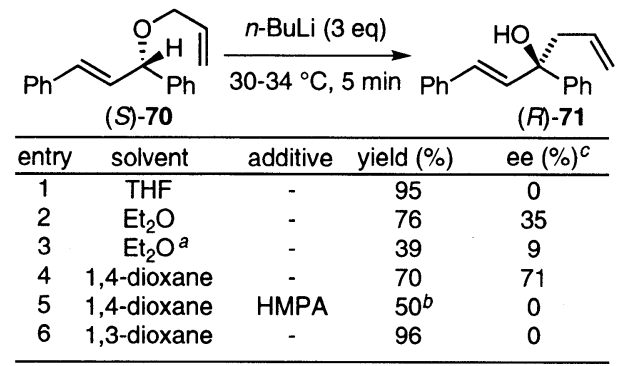

${ }^{a} t$-BuLi was used at $-80^{\circ} \mathrm{C}$. ${ }^{b} 40 \%$ of $(S)-70$ was recovered.

${ }^{c}$ Corrected for ee of the starting material $(99 \%$ ee)

\section{Acknowledgements}

This work has been possible because of the hard work and the dedication of past and present colleagues who are named in the references. This research was supported, in part, by a Grant-in-Aid for Exploratory Research, No. 14657563, a Grant-in-Aid for Scientific Research (B) 15390006, and a Grant-in-Aid for Scientific Research on Priority Areas 17035054 from the Japanese Ministry of Education, Sciences, Sports and Culture, the Uehara Memorial Foundation (KT), the Naito Foundation (KT), and the Sasakawa Scientific Research Grant from The Japan Science Society (MS). We thank Prof. Kentaro Yamaguchi of Tokushima Bunri University for X-ray crystallography. We also thank the Research Center for Molecular Medicine, Faculty of Medicine, Hiroshima University and the Natural Science Center for Basic Research and Development (N-BARD), Hiroshima University for the use of their facilities.

\section{References}

1) Eisch, J. J.; Trainor, J. T. J. Org. Chem. 1963, 28, 487.

2) Whitham, G. H. Science of Synthesis 2002, 4, 633.

3) (a) Stork, G.; Colvin, E. J. Am. Chem. Soc. 1971, 93, 2080. (b) Stork, G.; Jung, M. E. Ibid. 1974, 96, 3682.

4) For reviews on the Brook rearrangement, see: (a) Brook, M. A Silicon in Organic, Organometallic, and Polymer Chemistry, John Wiley \& Sons, Inc. 2000. (b) Brook, A. G.; Bassindale, A. R. In Rearrangements in Ground and Excited States; de Mayo, P. Ed.; Academic Press: New York, 1980; pp 149-221. (c) Brook, A. G. Acc. Chem. Res. 1974, 7, 77. For the use of the Brook rearrangement in tandem bond formation strategies, see: (d) Moser, W. H. Tetrahedron 2001, 57, 2065. Also, see: (e) Ricci, A.; Degl'Innocenti, A. Synthesis 1989, 647. (f) Page, P. C. B.; Klair, S. S.; Rosenthal, S. Chem. Soc. Rev. 1990, 19, 147. (g) Qi, H.; Curran, D. P. In Comprehensive Organic Functional Group Transformations, Katritzky, A. R.; Meth-Cohn, O.; Rees, C. W.; Moody, C. J., Eds.; Pergamon, Oxford, 1995, pp 409-431. (h) Cirillo, P. F.; Panek, J. S. Org. Prep. Proc. Int., 1992, 24, 553. (i) Patrocinio, A. F.; Moran, P. J. S. J. Braz. Chem. Soc. 2001, 12, 7.

5) (a) Takeda, K.; Fujisawa, M.; Makino, T.; Yoshii E.; Yamaguchi, K. J. Am. Chem. Soc. 1993, 115, 9351. (b) Takeda, K.; Ohtani, Y.; Ando, E.; Fujimoto, K.; Yoshii, E.; Koizumi, T. Chem. Lett. 1998, 1157. (c) Takeda, K.; Yamawaki, K.; Hatakeyama, N. J. Org. Chem. 2002, 67, 1786.

6) For reviews on homoenolate equivalents, see: (a) Ahlbrecht, H; Beyer, U. Synthesis 1999, 365. (b) Kuwajima, I.; Nakamura, E. Top. Curr. Chem. 1990, 155, 1. (c) Hoppe, D. Angew. Chem., Int. Ed. Engl. 1984, 23, 932. (d) Werstiuk, N. H. Tetrahedron 1983, 39, 205. (e) Werstiuk, N. H. In Umpoled Synthons; Hase, T. A. Ed.; John Wiley \& Sons: New York, 1987, p 173. Also, see: (f) Debal, A.; Cuvigny, T.; Larchevêque, M. Tetrahedron Lett. 1977, 3187.

7) (a) Takeda, K.; Kawanishi, E.; Sasaki, S.; Takahashi, Y.; Yamaguchi, K. Org. Lett. 2002, 4, 1511. (b) Sasaki, M.; Kawanishi, E.; Nakai, Y.; Matsumoto, T.; Yamaguchi, K.; Takeda, K. $J$.
Org. Chem. 2003, 68, 9330.

8) (a) Stork, G.; Boeckman, Jr. R. K. J. Am. Chem. Soc. 1973, 95, 2016. (b) Fleming, F. F.; Shook, B. C. Tetrahedron 2002, 58, 1.

9) Riddick, J.; Bunger, W. B.; Sakano, T. K. Organic Solvents: Physical Properties and Methods of Purification, 4th ed. (Technique of Chemistry, Vol. II); Wiley-Interscience: New York, 1986.

10) (a) Enda, J.; Kuwajima, I. J. Am. Chem. Soc. 1985, 107, 5495. (b) Kato, M,; Mori, A.; Oshino, H.; Enda, J.; Kobayashi, K.; Kuwajima, I. Ibid. 1984, 106, 1773.

11) Eliel, E.; Wilen, S. H. In Stereochemistry of Organic Compounds, John Wiley \& Sons: New York, 1994, p 696.

12) For reviews on base-promoted isomerization of epoxides, see: (a) Crandall, J. K.; Apparu, M. Org. React. 1983, 29, 345. (b) Satoh, T. Chem. Rev. 1996, 96, 3303.

13) For a base-promoted ring-opening of functionalized epoxides, see: (epoxy nitriles) (a) Fleming, F. F.; Wang, Q.; Steward, O. W. J. Org. Chem. 2001, 66, 2171. (epoxy amides) (b) Brooks, P. B.; Marson, C. M. Tetrahedron 1998, 54, 9613. (epoxy esters) (c) Mohr, P.; Rösslein, L.; Tamm, C. Tetrahedron Lett. 1989, 30, 2513. (d) Cory, R. M. Ritchie, B. M.; Shrier, A. M. Ibid. 1990, 31,6789 .

14) Matsumoto, T.; Masu, H,; Yamaguchi, K.; Takeda, K. Org. Lett. 2004, 6, 4367.

15) For bis-alkylation with $\alpha$-nitrile carbanions, see: (a) Mitani, M.; Takeuchi, H.; Koyama, K. Chem. Lett. 1986, 2125. (b) Fleming, I.; Loreto, M. A.; Wallace, I. H. M. J. Chem. Soc., Perkin Trans. 1 1986, 349. (c) Canonne, P.; Plamondon, J. Can. J. Chem. 1989, 67, 555 .

16) Enders, D.; Wiedemann, J.; Bettray, W. Synlett 1995, 369.

17) For this term, see: Little, D. R.; Dawson, J. R. Tetrahedron Lett. 1980, 21, 2609.

18) For some recent examples for MIRC, see: (a) Fioravanti, S.; Morreale, A.; Pellacani, L.; Tardella, P. A. Eur. J. Org. Chem. 2003, 4549. (b) Hassner, A.; Ghera, E.; Yechezkel, T.; Kleiman, V.; Balasubramanian,T.; Ostercamp, D. Pure Appl. Chem. 2000, $72,1671$.

19) (a) Yoshizaki, H.; Tanaka, T.; Yoshii, E.; Koizumi, T.; Takeda, K. Tetrahedron Lett. 1998, 39, 47. (b) Yoshii, E.; Hori, K.; Nomura, K.; Yamaguchi, K. Synlett 1995, 568. (c) Uyehara, T.; Shida, N.; Yamamoto, Y. J. Org. Chem. 1992, 57, 3139. (d) Hori, K.; Hikage, N.; Inagaki, A.; Mori, S.; Nomura, K.; Yoshii, E. Ibid. 1992, 57, 2888. (e) Hagiwara, H. J. Synth. Org. Chem. 1992, 50, 713. (f) Saito, S. J. Synth. Org. Chem. 1992, 50, 316.

20) (a) Okugawa, O.; Takeda, K. Org. Lett. 2004, 6, 2973. (b) Okugawa, S.; Masu, H.; Yamaguchi, K.; Takeda, K. J. Org. Chem. 2005, 70, 10515-10523.

21) Although the possibility of a silicate transition state cannot be ruled out, we believe that the species is likely to be involved on the basis of results of our previous work and calculations ${ }^{22}$ of the structure in the gas phase. Tanaka, K.; Masu, H.; Yamaguchi, K.; Takeda, K. Tetrahedron Lett. 2005, 46, 6429.

22) (a) Antoniotti, P. ; Tonachini, G. J. Org. Chem. 1993, 58, 3622. (b) Antoniotti, P.; Canepa, C.; Tonachini, G. Ibid. 1994, 59, 3952. Also, see: (c) Fleming, I.; Lawrence, A. J.; Richardson, R. D.; Surry, D. S.; West, M. C. Helv. Chim. Acta 2002, 85, 3349.

23) Elimination reactions of $\alpha$-oxidosilanes with a $\beta$-leaving group are known to proceed in an anti manner. Hudrlik, P. F.; Hudrlik, A. M.; Kulkarni, A. K. J. Am. Chem. Soc. 1985, 107 , 4260-4264.

24) For discussions on stereochemistry of Brook rearrangement of $\alpha$-silyl alkoxides bearing an $\alpha, \beta$-leaving group, see: Reich, $\mathrm{H}$. J.; Holtan, R. C.; Bolm, C. J. Am. Chem. Soc. 1990, 112, 5609.

25) Cyclopropane ring-opening by a carbanion generated by Brook rearrangement has recently been reported. Clayden, J.; Watson, D. W.; Chambers, M. Tetrahedron 2005, 61, 3195.

26) Sasaki, M.; Takeda, K. Org. Lett. 2004, 6, 4849.

27) (a) Nicolaou, K. C.; Harter, M. W.; Gunzner, J. L.; Nadin, A Liebigs Annalen/Recueil 1997, 1283. (b) Mann, S.; Carillon, S.; Breyne, O.; Marquet, A. Chemistry-A European Journal 2002, 8, 439.

28) (a) Chinchilla, R.; Najera, C. Chem. Rev. 2000, 100, 1891. (b) Funk, R. L.; Bolton, G. L. J. Am. Chem, Soc. 1988, 110, 1290 (c) Pohmakotr, M.; Pisutjaroenpong, S. Tetrahedron Lett. 1985, 26, 3613. (d) Reich, H. J.; Clark, M. C.; Willis, W. W., Jr. J. Org. Chem. 1982, 47, 1618. (e) Ogura, K.; Iihama, T.; Takahashi, K.; Iida, H. Tetrahedron Lett. 1984, 25, 2671. (f) Clinet, 
J.-C.; Linstrumelle, G. Ibid. 1980, 21, 3987. (g) Cohen, T.; Bennett, D. A.; Mura, A. J., Jr. J. Org. Chem. 1976, 41, 2506. (h)Wada, M.; Nakamura, H.; Taguchi, T.; Takei, H. Chem. Lett. 1977, 4, 345. (i) Kondo, K.; Tunemoto, D. Tetrahedron Lett. 1975, 1007. (j) Nakai, T.; Shiono, H.; Okawara, M. Ibid. 1974, 3625. (k) Leroux, Y.; Mantione, R. Ibid. 1971, 591.

29) Treatment of pyridin-2-sulfinyl derivative with NAHMDS in the presence of benzyl bromide afforded a complex mixture. Although a similar result was obtained with both phenylsulfonyl and $p$-toluenesulfonyl derivatives, the latter is superior in terms of crystallizability.

30) Tanaka, K.; Takeda, K. Tetrahedron Lett. 2004, 45, 7859.

31) Takeda, K.; Ohnishi, Y. Tetrahedron Lett. 2000, 41, 4169.

32) For a silicate intermediate in Brook rearrangement, see: Takeda, K.; Yamawaki, K.; Hatakeyama, N. J. Org. Chem. 2002, 67, 1786. and ref. 20.

33) Linghu, X.; Nicewicz, D. A.; Johnson, J. S. Org. Lett. 2002, 4, 2957.

34) Okamoto, N.; Sasaki, M.; Kawahata, M.; Yamaguchi, K.; Takeda Org. Lett. 2006, 8, 1889.

35) The use of lithium and sodium enolates resulted in recovery of the starting material and a lower yield of 14, respectively.

36) Sasaki, M.; Higashi, M.; Masu, H.; Yamaguchi, K.; Takeda, K. Org. Lett. 2005, 7, 5913.

37) (a) Johnson, R. A.; Sharpless, K. B. In Catalytic Asymmetric Synthesis; Ojima, I., Ed.; Wiley-VCH: New York, 1993; pp 101-158. (b) Jacobsen, E. N. In Catalytic Asymmetric Synthesis: Ojima, I., Ed.; Wiley-VCH: New York, 1993; pp 159-202. (c) Frohn, M.; Shi, Y. Synthesis 2000, 1979.

38) For reviews on $[2,3]$-Wittig rearrangement, see: (a) Nakai, T.; Mikami, K. Chem. Rev. 1986, 86, 885. (b) Marshall, J. A. In Comprehensive Organic Synthesis; Trost, B. M., Fleming, I., Eds.; Pergamon: Oxford, 1991; Vol. 3, pp 975-1014. (c) Mikami, K.; Nakai, T. Synthesis 1991, 594. (d) Nakai, T. Mikami, K. Org. React. 1994, 46, 105. (e) Nakai, T.; Tomooka, K. Pure Appl. Chem. 1997, 696, 595 .

39) To the best of our knowledge, the solvent has not been used in [2,3]-Wittig rearrangement, probably because the rate of racemization of the carbanion has been thought to be much faster than that of the reaction with an electrophile at temperatures higher than its freezing point $\left(11{ }^{\circ} \mathrm{C}\right)$.

40) (S)-71 was prepared from cinnamaldehyde by a three-step sequence: (1) PhLi, (2) kinetic resolution according to the protocol of Sharpless, and (3) $\mathrm{BrCH}_{2} \mathrm{CH}=\mathrm{CH}_{2}$.

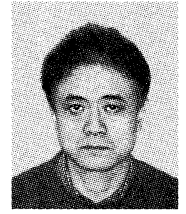

Kei Takeda is professor of organic chemistry at Hiroshima University. He was born in 1952 and received both his B.S degree (1975) and M.S. degree (1977) from Toyama University (Professor Eiichi Yoshii) and his Ph.D. degree from the University of Tokyo (1980), where he studied under Professor Toshihiko Okamoto. In 1980, he joined the faculty at Toyama Medical and Pharmaceutical University (Prof. Yoshii's group). After working as a visiting scientist at MIT with Professor Rick L. Danheiser (1988-1989), he was promoted to Lecturer (1989) and then to associate professor (1996). He was the recipient of the Sato Memorial Award (1998). He became a professor of Hiroshima University in 2000 . His research interests are in the invention of new synthetic reactions and their application to complex organic molecules.

Michiko Sasaki is an assistant professor of organic chemistry at Hiroshima University. She obtained her B.S. degree (2002), M.S. degree (2003), and Ph.D. degree (2006) from Hiroshima University under the direction of Professor Kei Takeda. Her current research interests lie in the area of development of new synthetic reactions. 